\title{
The Social Practice of Sustainable Agriculture under Audit Discipline: Initial Insights from the ARGOS Project in New Zealand. ${ }^{1}$
}

\author{
Hugh Campbell, Chris Rosin, Lesley Hunt and John Fairweather.
}

\begin{abstract}
One of the most interesting recent developments in global agri-food systems has been the rapid emergence and elaboration of market audit systems claiming environmental qualities or sustainability. In New Zealand, as a strongly export-oriented, high-value food producer, these environmental market audit systems have emerged as an important pathway for producers to potentially move towards more sustainable production. There have, however, been only sporadic and fractured attempts to study the emerging social practice of sustainable agriculture - particularly in terms of the emergence of new audit disciplines in farming. The ARGOS project in New Zealand was established in 2003 as a longitudinal matched panel study of over 100 farms and orchards using different market audit systems (e.g., organic, integrated or GLOBALG.A.P.). This article reports on the results of social research into the social practice of sustainable agriculture in farm households within the ARGOS projects between 2003-2009. Results drawn from multiple social research instruments deployed over six years provide an unparalleled level of empirical data on the social practice of sustainable agriculture under audit disciplines. Using 12 criteria identified in prior literature as contributing a significant social dynamic around sustainable agriculture practices in other contexts, the analysis demonstrated that 9 of these 12 dimensions did demonstrate differences in social practices emerging between (or co-constituting) organic, integrated, or conventional audit disciplines. These differences clustered into three main areas: 1 ) social and learning/knowledge networks and expertise, 2) key elements of farmer subjectivity - particularly in relation to subjective positioning towards the environment and nature, and 3) the role and importance of environmental dynamics within farm management practices and systems. The findings of the project provide a strong challenge to some older framings of the social practice of sustainable agriculture: particularly those that rely on paradigm-driven evaluation of social motivations, strong determinism of sustainable practice driven by coherent farmer identity, or deploying overly categorical interpretations of what it means to be 'organic' or 'conventional'. The complex patterning of the ARGOS data can only be understood if the social practice of organic, integrated or (even more loosely) conventional production is understood as being co-produced by four dynamics: subjectivity/identity, audit disciplines, industry cultures/structure and time. This reframing of how we might research the social practice of sustainable agriculture opens up important new opportunities for understanding the emergence and impact of new audit disciplines in agriculture.
\end{abstract}

\footnotetext{
${ }^{1}$ We would like to acknowledge the contribution of many members of the Agriculture Research Group on Sustainability (ARGOS): particularly, Jon Manhire, Henrik Moller, Caroline Saunders, John Reid, Jason Benge, David Lucock, Grant Blackwell, Bill Kaye-Blake, Martin Emanuelson, Carmen McLeod, Solis Norton, Peter Carey and Glen Greer. We also wish to acknowledge the work of student interns and research assistants: Marion Reid, Andrew Cook, Caela O'Connell, Philippa Baird and Leah Rothbaum. The article has also benefited from wider constructive discussion of the emerging ARGOS social research methodology with Julia Haggerty, Julie Guthmann, Richard Le Heron, Mark Shucksmith, Janet Grice, Rob Burton, Paul Stock and Sue Peoples. Finally, we would also like to thank three anonymous referees for their positive and useful comments.
} 


\section{Introduction}

This article provides a summary of social research findings from the first stage of the long-term Agriculture Research Group on Sustainability (ARGOS) Project in New Zealand. Within the transdisciplinary framework of the project, the key research question for the social scientists addressed the extent to which new market audit systems (like certified organic or GLOBALG.A.P.) helped to define the social dynamics of the commercial farms using them. This focus enabled us to address the paucity of empirical material available on the social dynamics of farm households undertaking certified organic or other 'sustainability' audited systems of production. The analysis of the resulting data further exposed and provided a means to reduce a gap in the sociological narrative of sustainable agriculture that has, it will be argued, failed to adequately conceptualise these audit systems as rapidly emerging mechanisms that discipline significant segments of the global agri-food system. The general lack of in-depth empirical social research into farm households adopting sustainability audit systems also limits the capability of social researchers to assess the validity of wider public claims by the likes of Michael Pollan that commercialised organic agriculture has 'sold out' or now significantly mimics conventional agricultural systems both economically and socially. ${ }^{2}$ In other words, has the introduction of audit disciplines in order to secure 'sustainability' claims in alternative food chains significantly, and negatively, changed the social character of alternative approaches like organic agriculture as clearly implied by such claims?

This article, therefore, examines the social dynamics and practices emerging around the sustainability audits that are appearing in food supply chains around the world. ${ }^{3}$ It does so by drawing on data from the ARGOS project - arguably the largest current study into farm-level sustainability in the world - which has been gathering social, economic and ecological data on over 100 farms and orchards in New Zealand since 2003 (www.argos.org.nz). The data from this project provide a compelling resource for evaluating the social (and ecological and economic) dynamics associated with the disciplining of commercial-scale family farms by market-audit systems. The resulting complex picture of social practices under different audit disciplines fills some key gaps in the empirical narrative of the social practice of sustainable agriculture and, in the process, establishes a strong challenge to the framing and mobilisation of such social practices in some existing analytical frameworks.

\section{The Social Practice of Sustainable Agriculture under Audit}

One of the most compelling aspects of recent transformations of global agri-food systems has been the emergence of audit culture as an important new form of food governance. Responding to these changes, a range of scholars have attempted to understand the dynamics, scope and implications of these audits and the disciplining they operationalise in agri-food systems (see Busch and Bain 2004, Campbell 2005, Hatanaka et al. 2005, Henson and Reardon 2005, Jahn et al. 2005, Fulponi 2006, Rosin 2008). The conclusion reached by all these scholars is that food audits, standards, grades and

\footnotetext{
${ }^{2}$ For a fuller discussion of the implications of Pollan's 'Organic Industrial Complex' (2001) see Campbell and Rosin (2011).

${ }^{3}$ For the purposes of this discussion, the term 'audit' is used to designate a broad cluster of dynamics around inspection, certification, standards, protocols, traceability systems, along with their associated labelling and branding claims that make up what Power (1997) calls 'audit culture'.
} 
protocols are among the most influential and theoretically interesting new dynamics within contemporary agri-food systems - particularly those involving high-value markets or supplying highend retailers in regions like Europe and Japan. The new audit disciplines have, in part, developed in parallel with the deployment of sustainability claims in high-value food products. Certified organic agriculture offers an early example of this new food audit culture and key associated features: the implication of values associated with sustainability, the use of third party certification, strong linkages to both a long-term social movement as well as the new strategies of multiple retailers, and rapid growth in high-value markets (Campbell and Le Heron 2007). Alongside certified organic, a parallel body of standards and audits has emerged around 'integrated' systems ${ }^{4}$ designed to supply multiple retailers with branded products that can support claims of 'sustainable' and 'safe' production without being specifically organic. The most notable of these has been the EurepGAP (now GLOBALG.A.P.) audit alliance, which has rapidly spread among European retailers (Campbell 2005).

The increasing importance of these new audits, grades, standards and certification processes as features of agri-food systems raises the key question that will be the focus of this article. Namely, for farmers and orchardists, what is the distinguishing social character of being certified 'organic' or 'integrated' as compared to 'conventional'? This question is approached from two distinct perspectives: a) what are the social practices that influence the engagement of farmers/growers with these audit systems as disciplining mechanisms, and b) how are the social characteristics of, and social practices in and around, farm households and farm decision-makers both influenced by and structuring of the outcomes of the introduction of these systems?

A small body of literature has engaged with specific aspects of the social practice of sustainable agriculture more generally. The work of scholars like Mears (1997), Peter et al. (2000) and Liepins (1995) raised the importance of gender dynamics in the context of sustainable agriculture. Similar questions have been raised about grower identity/subjectivity (Burton 2004a, 2004b, Bell 2004), subjective positioning towards the environment (Wilson 1996, Holloway 2002), acquisition of skill and construction of knowledge (Hassanein 1999, Morgan and Murdoch 2000), community networks and social capital (Flora 2001, Lyson 2004), and farming styles (Vanclay et al. 2006). Together, these create an initial impression of what kind of social practices might be associated with farm householders and decision-makers engaged in sustainable agriculture. This includes dynamics around: farm decision-making, social networks, learning styles and approaches, subjective positioning around key issues like the importance of the farm environment, willingness to trade off environmental and economic goals and the influence of social factors on management decisions around farm production. Together, these form the outlines of what, for the purposes of this article, we term the 'social practice' of sustainable agriculture. By using the term social practice, we are intentionally moving beyond the descriptive quality of social 'characteristics' of farm households and individuals engaged in sustainable agriculture by seeking to also understand the dynamic quality of: decision-making, social networks, learning, subjectivities, management approaches and embodied

\footnotetext{
${ }^{4}$ Commencing with protocols around Integrated Pest Management (IPM) and the goal of low-residue products, audit systems like EurepGAP/GLOBALG.A.P. evolved to incorporate a range of measures and dimensions beyond those originally encapsulated in IPM. While significant in scope and scale, these new and elaborating environmental audit systems have yet to be ascribed a stable collective noun. For this article, the term 'integrated' is used as a brief descriptor of this emerging group of post-IPM, environmental (but nonorganic) certification systems.
} 
activities as they are practiced, enacted and reproduced within and around farm households. We are particularly interested with such social practice in the context of audit-disciplined approaches to sustainable farm management.

\section{After ACAP: Reframing Social Practice in Sustainable Agriculture}

If we permit the idea that there is or are multiple bodies of social practice associated with the emergence of sustainable agriculture, how do we start to assemble a framework to assess the means through which these practices are influencing (and are influenced by) actual farm management? Put simply, how do we understand whether social practice actually has any coherent relationship with management and environmental praxis on farms?

In situating social practice at the centre of this discussion, this article seeks to break with one of the most dominant frameworks to the sociological analysis of sustainable agriculture: the Alternative Conventional Agricultural Paradigms (ACAP) dichotomy of Curtis Beus and Riley Dunlap (see Beus and Dunlap 1990, 1991, 1994). This approach provided a powerful framing of social research into sustainable agriculture in the 1990s and is still influential in more recent work (e.g., Hall and Mogyorody 2007, Fulkerson 2008, Stofferahn 2009) despite strong critiques based in subsequent attempts to replicate the dichotomy in survey research (Jackson-Smith and Buttel 2003). The ACAP framework was important and influential in that it attempted to move beyond single 'social dimensions' and assemble a set of coherent and interlocking attributes underpinning farmers' (and other actors') decisions about and dispositions towards sustainable or conventional agriculture. Its application was constrained, however, by a reliance on the notion of distinct, and opposing, 'paradigms' of social orientation between conventional and alternative producers.

While less importance has been placed on the specifics of the framework over the subsequent years, the persistent core of this approach has become - in our contention - emblematic of a particular (and problematic) sociological approach to sustainable agriculture. Beus and Dunlap (1990, 1991, 1994) implied a unity or integrity to the overall configuration of the differentiated identity 'paradigms' of alternative and conventional producers that enabled the construction of a strong and categorical binary between the bodies of social practice they employed. The presence of this concrete binary forms the first key framing assumption of their approach. The ACAP framework also incorporates a second key assumption (particularly as used in some activist contexts): that the actual praxis of on-farm sustainability is largely driven by a coherent set of (paradigmatic) attributes embedded within the identities of farmers. The logic of this assumption aligns with the wider, and now long discarded, framework in social psychology which assumes that attitudes predict behaviours in a reasonably linear way. ${ }^{5}$ Put simply, the failure to express the identity characteristics of an 'authentic' organic farmer is grounds for suspecting that actual on-farm practices are not organic. A farmer's 'organic-ness' is situated in a purportedly coherent 'identity' or set of 'attitudes', thus making the actual behaviours that comprise the social practice of sustainable agriculture merely derivative thereof. In this approach, it is conceptually impossible to (socially) be less than wholeheartedly organic and any attempt to do so is automatically worthy of suspicion. This kind of social logic implicitly underpins the critique by the like of Michael Pollan that many recently certified organic growers are, at some sociological level, not 'real' organic.

\footnotetext{
${ }^{5}$ For a fuller discussion of this problem as a launching point for a more sophisticated construction of the social psychology of environmental action see Burton (2004b).
} 
The arrival of new audit-based approaches for authenticating claims of 'sustainability' raises perplexing issues for attempts to understand the social practice of sustainable agriculture within these old framings. Whereas 20 years ago the practice of organic (as the predominant form of alternative) agriculture was entirely driven by the dynamics of social movements, now it is almost completely subject to the aegis of audit and certification systems. At the same time, new supermarket systems like GLOBALG.A.P. are compulsory in many supply chains regardless of whether participating farmers are subjectively well-disposed towards environmental production standards or not. This tension between farmer motivation and external audit disciplines has been expressed through the scholarly mobilisation of differential framings like 'pragmatic organic' versus 'committed organic' in order to describe technically compliant growers who do not subjectively position themselves as paradigmatically organic (e.g., Fairweather 1999, Darnhofer et al. 2005). Similarly, the mobilisation of the terms 'conventionalisation' and 'bifurcation' reflect simple means of accounting for both a philosophically-committed group of good/authentic organic growers motivated by core subjectivity, and a bad/pragmatic group who are merely disciplined by audit and motivated by profit.

The emergence of audit culture within the world of commercialised food qualities like organics has challenged the ability of early framings of sustainable agriculture like the ACAP framework to establish a simple linear relationship between alternative (or conventional) agriculture as an identity/paradigm and actual on-farm changes in social/environmental praxis. Yet some of the newer ways of trying to grasp this complexity - like the ideas of conventionalisation and bifurcation - are also unsatisfactory for grasping the disruptive complexities of sustainable agriculture under audit (Rosin and Campbell, 2009). Clearly, we need new approaches and frameworks for understanding the social practice of sustainable agriculture in an age of audit culture. In this article, the data collected within the ARGOS project is used to demonstrate a more complex and coproduced set of social practices than that represented in the kind of binary and identity/paradigmdriven framing mobilised in ACAP.

This article will outline the analytical and methodological process that eventually created a reframing of the social practice of sustainable agriculture through the lens of dynamic coproduction. The next sections detail how the social research findings reported in this article emerged from within a much wider research project into sustainable agriculture in New Zealand spanning multiple disciplines and collecting data on farms and farm households over a number of years. The first stage of analysis of the social research data collected in the ARGOS project provides an examination of a structured process of investigation of 12 social characteristics and/or dynamics that prior research had identified as having potential relevance to the social practice of sustainable agriculture. Drawing on findings from a range of published analyses of ARGOS social research data, it is evident that there are strong differences between panels of producers arranged according to adherence (or not) to market audit systems. The second stage of the analysis demonstrates how these differences cluster around aspects of: 1) grower networks and learning networks, 2) grower subjectivity, positioning towards the environment, and 3) key aspects of on-farm management practice (including the situation of the environment in management practice). The final stage of the analysis seeks to reframe these social differences that have emerged and are structured across the ARGOS data into an understanding of the dynamic co-production of the social practice of sustainable agriculture. This dynamic co-production of the social practice of sustainable agriculture emerges from the interplay of: 1) grower subjectivity, 2) audit disciplines, 3) industry dynamics and 4) time 
and provides a compelling and complex alternative to the earlier ways of framing the social practice of sustainable agriculture.

\section{The Significance of New Zealand as a Study Site}

New Zealand has a highly productive primary production system which is well suited to facilitate the conceptualisation and examination of the emergence of new food audit cultures around organic and other sustainable systems (Le Heron 2003). As one of the most neoliberalised agricultural production systems in the world, the 'roll back' of state regulation food and fibre exports incentivised considerable innovation, networking, and integration with wider global processes of auditing and other new styles of governance (Larner and Le Heron 2004, Larner et al. 2007, Le Heron $2005,2007)$. As a result, New Zealand was a notable early exporter of certified organic and integrated produce and has received considerable attention from researchers interrogating the intersection of market-derived food audit disciplines and sustainability. Alongside the benchmark Californian work of Julie Guthman (Buck et al. 1997, Guthman 1998, 2004), New Zealand-based research provided some of the first observable cases of large-scale commercial organic production (Campbell 1997, Coombes and Campbell 1998, Campbell and Coombes 1999, Campbell and Liepins 2001). During the last 15 years, the emergence of large volumes of horticultural exports using integrated protocols or adhering to the new supermarket audit alliance EurepGAP/GLOBALG.A.P. also positioned New Zealand as a key early case of new food auditing more generally (see McKenna et al. 1998, Campbell 2005, Campbell et al. 2006, Rosin 2008, Rosin et al. 2007a, 2007b, 2007c).

Consequently, by the early 2000s, New Zealand agriculture was increasingly defined by the adoption of new audit systems making sustainability claims. Its export industries were strong participants in the development and consolidation of both certified organic agriculture and of global governance arrangements like EurepGAP/GLOBALG.A.P. and were recognised as such through the attention of multiple researchers. It provided, in short, the ideal national setting for a research project seeking to understand the long-term implications of achieving sustainability goals via market audit disciplines.

\section{The ARGOS Research Programme: 2003-2009}

In 2001-2002, a series of discussions took place among a group of scholars that would later be formally titled the Agriculture Research Group on Sustainability (ARGOS). Commencing in 2003, the ARGOS group succeeded in securing a large grant from the New Zealand government and a series of smaller contracts to support the establishment of a long-term study of over 100 farms and orchards, which were complying with emerging market audit systems. ${ }^{6}$ ARGOS selected participating farms and orchards in order to facilitate direct comparison of certified organic, audited integrated systems, and continuing 'conventional' production (i.e., not using any kind of 'sustainable' market audit system although oftentimes still required to meet specific production standards). The programme was explicitly designed to evaluate the social, economic and ecological effects of taking market audit pathways to sustainability. This article reports only the results of social research during the first six years of the ARGOS Programme (2003-2009).

When the ARGOS group was designing the research programme in 2002-2004, a series of methodological challenges were identified as to how the effects of new market audit systems might

\footnotetext{
${ }^{6}$ New Zealand has around 60,000 commercial farms, the majority of which are still operated by families.
} 
be evaluated (see Manhire et al. 2003, Campbell et al. 2009). Three key elements of the ARGOS research design emerged from this discussion. First, it would be cross-disciplinary, as sustainability issues tend not to respect disciplinary boundaries. Each farm/orchard was examined in terms of social, economic and ecological dynamics relating to the adoption of a market-audit system. Second, it would be longitudinal, as the interactions between different aspects of the farming system often unfold over time, with the long term effects of deploying a new audit system potentially only appearing after many years. Finally, most of the 100+ farms and orchards were arranged in panels (three panels in the Sheep/Beef and Kiwifruit sectors and two in the Dairy sector) each panel representing different market audit-defined management systems (see Table 1). Each sector had an organic panel, which was then compared to panels of integrated and/or conventional (depending on the options available in each industry sector).

Table 1: Panels of participating ARGOS Farms/Orchards ${ }^{7}$

\begin{tabular}{|c|c|c|c|c|}
\hline & Conventional & Integrated & Organic & Total \\
\hline \hline Kiwifruit & $\begin{array}{c}12 \\
\text { Integrated Green } \\
\text { (GLOBALG.A.P.) }\end{array}$ & $\begin{array}{c}12 \\
\text { Integrated Gold } \\
\text { (GLOBALG.A.P.) }\end{array}$ & 12 & 36 \\
\hline Dairy* & 12 & 0 & 12 & 24 \\
\hline $\begin{array}{c}\text { Sheep/beef } \\
\text { Lowland }\end{array}$ & 12 & 12 & 13 & 37 \\
\hline
\end{tabular}

*There is no integrated option available in the dairy sector.

Geographically proximate clusters including representative farms/orchards from each panel were organised across New Zealand to account for ecological variation in comparisons. Thus, the farms or orchards in a cluster ideally shared contiguous boundaries and were comprised of similarly sized, family-run commercial farms/orchards.

\section{Social Research in ARGOS: Methods and Key Themes}

Social research was embedded at the early stages of the planning process as one of the three key investigative strands of the ARGOS project. The social research team used a mixed set of research instruments ranging from semi-structured qualitative interviews, causal mapping of farming

\footnotetext{
${ }^{7}$ These 97 properties were supplemented with another 10-12 case studies of High Country sheep/beef or Maori land holdings. Numbers have varied through the life of the project due to slight attrition in some panels. ${ }^{8}$ There is no 'conventional' production in the New Zealand kiwifruit industry with the entire industry converting to integrated or organic in the late 1990s. Hence, the distinction between 'integrated green' (more mainstream panel producing the 'green' variety of kiwifruit) and 'integrated gold' (the newer, more intensive and higher value panel producing the new 'gold' kiwifruit).
} 
systems, sketch mapping of the farm landscape, and questionnaire surveys of both ARGOS farmers and random samples of New Zealand farmers. ${ }^{9}$

There were three styles of data collection:

1. Qualitative Interviews with the primary decision maker(s) for the farm operation. Each farm was visited twice in order to conduct two semi-structured, in-depth interviews. For each interview, a number of key questions were used as a guide to the process but in large part the intention was to explore and record farmer responses in order to obtain a rich account of farming life from the point of view of the farmers.

2. Other semi-structured methods were used to gain insight into particular topics. One such method was causal mapping which was developed and applied in such a way as to allow the farmers to identify the important elements in their farm system, and to show how these elements causally interact (see Fairweather and Hunt 2009). Another similar method was farm sketch mapping in which farmers were asked to draw a map of their farm landscape.

3. Two random sample surveys of the New Zealand farm population as a whole were conducted. These focused on the three main sectors (sheep/beef, dairy and horticulture) and on the three management systems (conventional, integrated and organic) with results broken down by these main categories. In parallel to the national surveys, all ARGOS farmers completed the questionnaires facilitating analysis of the extent to which the ARGOS farms were representative of the wider farm population (Fairweather et al. 2007b).

Table 2: Social Research Instruments in ARGOS from 2003-2009

\begin{tabular}{|l|l|l|}
\hline Research Instrument & Year & Publications \\
\hline $\begin{array}{l}1^{\text {st }} \text { Qualitative Interview } \\
\text { (Kiwifruit, Sheep/Beef) }\end{array}$ & 2004 & Hunt et al. (2005, 2006) \\
\hline Sketch Maps by Farmers & 2004 & Read et al. (2005) \\
\hline $\begin{array}{l}\text { Causal Mapping of Farm } \\
\text { Systems }\end{array}$ & $2004-2006$ & $\begin{array}{l}\text { Fairweather et al. (2006, 2007a, } \\
\text { 2009a), Fairweather and Hunt } \\
\text { (2009), Fairweather (2009). }\end{array}$ \\
\hline $\begin{array}{l}1^{\text {st }} \text { National Survey (including all } \\
\text { ARGOS farmers) }\end{array}$ & 2005 & $\begin{array}{l}\text { Fairweather et al. (2007b, } \\
\text { 2007c) }\end{array}$ \\
\hline $\begin{array}{l}2^{\text {nd }} \text { Qualitative Interview } \\
\text { (Kiwifruit, Sheep/Beef; Dairy- } \\
\text { combined with 1 }\end{array}$ & 2006 Interview) & $\begin{array}{l}\text { Rosin et al. (2007a, 2007b), } \\
\text { Mortlock and Hunt (2008) }\end{array}$ \\
\hline $\begin{array}{l}2^{\text {nd }} \text { National Survey (including } \\
\text { all ARGOS farmers) }\end{array}$ & 2008 & Fairweather et al. (2009b) \\
\hline
\end{tabular}

\footnotetext{
${ }^{9}$ The specific methods and results of each of these instruments are published in the reports and articles listed in Table 2.
} 
These research instruments addressed the key question in the ARGOS project: what are the relative impacts or outcomes of a farm/orchard complying with market audit disciplined management systems (organic or integrated) or remaining in conventional production?

In order to begin to address this question and as there had been no parallel project in style or scope to ARGOS, a literature review was conducted (in 2003-2004) to identify key social dynamics of sustainable agriculture systems identified by social researchers in other contexts (Campbell et al. 2004). The review of a broad range of literatures revealed the following potentially salient social dynamics in relation to the social practice of sustainable agriculture. This list was supplemented from pilot discussions during 2003/04 with participating grower groups, farm households and agricultural consultants working with organic growers.

1. Demographic Characteristics: The key demographic characteristic discussed in the early social research literature on sustainable agriculture was gender (Mears 1997, Peter et al. 2000, Liepins 1995, Liepins and Campbell 1997). There was also speculation over the influence of age, level of education, ethnicity, farming background, and religious participation (Falconer 2000, Ondersteijn et al. 2003, Paterson 2001).

2. Family Farming - the Class, Ownership and Enterprise Structure of Farming: At the time ARGOS social research was being designed, the wider theoretical questions of the 'New Rural Sociology' were highly influential. In particular, the problematic role of agribusiness corporations in commercialising organic agriculture (Buck et al. 1997, Guthman 2004), the compatibility of capitalist economic structures and sustainable agriculture (Allen et al. 1991, Allen and Kovach 2000), sustainable agriculture and leasehold (Carolan 2005), life cycle stage, and the economic structure of farm households and the opportunities for alternative agriculture (Bell 2004).

3. Grower Identity and Change: Alongside the ACAP framing of coherent paradigms of alternative and conventional practice, a growing body of research, particularly in Europe and the US, examined issues of grower identity; individual subjectivities, or farming habitus, and its influence on or interaction with on-farm environmental practice; or the relative interactive influence of such practices with cultural notions of 'good farming' (for a summary see Burton 2004a, 2004b).

4. Positioning towards Nature/Environment: A specific subset of the previous category was farming individuals' positioning relative to and constructed understandings of nature, the farmed environment and environmental practices (e.g., Wilson 1996, Holloway 2002, Bell 2004).

5. Industry Context, Economic and Craft Orientation: This period experienced ongoing and highlevel political conflict around neoliberal deregulation of export organisations, including the political positioning of organic producers in these conflicts (McKenna and Campbell 1999). A parallel debate pertains to whether agri-food chains are configured around long or short chains, commodity or craft/quality production, (e.g., Hinrichs 1998, 2000) or the autonomy of growers/farmers in relation to industry requirements.

6. Sense of Place and Symbolic 'Look' of Farmscape: Wes Jackson's essay 'Becoming Native to Place' (Jackson 1994) was widely discussed across the ARGOS research team as a shared point of engagement between the social researchers and those interested in indigenous land-management dynamics in New Zealand and in farmers' sense of bonding to their 
particular piece of land or attachment to farming locality. A specific aspect of this is the symbolic 'look' of farmscapes as identified by Egoz (2000) on organic farms in New Zealand.

7. Learning, Skill and Expertise: Prior literature strongly identifies the need for sustainable agriculture to break with mainstream expertise and learning systems (Hassanein 1999, Hassanein and Kloppenburg 1995). Are alternative farmers 'systems thinkers' and/or are they able to mobilise what Pretty (2002) calls 'ecological literacy'?

8. Grower Stress and Wellbeing: During early consultation with growers groups and organic farmers, issues of stress and wellbeing were raised as a potentially important dynamic in farm households.

9. Community and Grower Networks: Many authors have suggested that alternative agriculture could be better for the long-term viability of rural communities in countries like the US (see Flora 2001). This could operate in terms of direct food and economic linkages between farming and rural communities or, at a more discursive level, around the perceived importance of communities and networks.

10. Indicators of On-Farm Processes/Feedbacks: Discussion with ecological scientists in the ARGOS group highlighted the different kinds of indicators farmers might use to assess the environmental, economic or social health of their operation. Is the claim true that growers who observe and respond to a greater number of ecological feedbacks will be more sustainable? ${ }^{10}$

11. Farm Management Approaches: A large literature involves the overlap between orthodox farm management analysis and a more sociological approach to dynamics like 'farming styles' (for a later review see Vanclay et al. 2006). Within these styles lie strategically and tactically varying responses to issues like risk, innovation, control and timeframes for decision-making.

12. Social Capital in Relation to Management System: An alternative approach to the examination of social networks (relations with other farmers, organisations, sources of information or other benefits, etc.) utilises the concept of social capital. The literature argues that greater social capital contributes to the sustainability and viability of agricultural production (Pretty and Ward 2001, Pretty 2002).

These 12 potential topics (and their implicit questions) framed the initial enquiry into the social practices of the farm households and therefore form the initial point from which the empirical findings of six years of research activities can be evaluated. They were not deployed as isolated variables, but rather were used to construct question sets, and also to inform research into how these might cluster or interact (e.g., in potentially coherent patterns or systems as expected by ACAP-style analysis). Particular emphasis was placed on their interaction with the panel structure of the ARGOS sample.

\section{Interrogating the Original 12 Social Dynamics using ARGOS Social Data}

It is useful to interrogate how the clustering of the key social dynamics emerges in relation to the expectations of the literature review. The following results reflect a comparative analysis based on the management system panel to which each farm/orchard was assigned (i.e., organic, integrated,

${ }^{10}$ Subsequent literature has begun to elaborate this potential set of dynamics (e.g., Sundkvist et al. 2005). 
conventional). Accordingly, the data are discussed primarily in terms of differences between panels in each sector. While it would have been useful for the narrative in this article to simply use the terms 'organic', 'integrated' and 'conventional' to describe management panels, the different sectors had different configurations of management panels reflecting the different market audit options available. Hence, while all three sectors had an 'organic' panel, the kiwifruit sector had two 'integrated' panels (integrated green kiwifruit and integrated gold kiwifruit). Panels can, nonetheless, be used to demonstrate the structuring effect of market audit defined management systems in the social data.

The first result was that 3 of the 12 social dynamics provided no grounds for differentiating between the panels:

1. Demographic differences. There were no significant differences in the age, gender or level of education of the panels (Fairweather et al. 2007b). However, such differences were evident in a larger survey of New Zealand farmers in which organic growers tended to be younger and better educated (Fairweather et al. 2007c), suggesting that the ARGOS panels comprised too small a sample to allow broad demographic patterns to be identified.

2. Family Farming - the Class, Ownership and Enterprise Structure of Farming. Again, no significant differences were found in any of the quantitative questions or qualitative data around this set of dynamics. There were, however, interesting differences in the structuring of farm and orchard households between sectors rather than management panels. In short, the nature and character of production in the three sectors (kiwifruit, dairy, sheep/beef) creates demands on farm structure, labour and enterprises that overwhelm any differences between the management panels (e.g., organic, integrated, conventional). This distinction becomes quite important in our subsequent interpretation.

3. Social Capital. Data relevant to social capital did not reveal any differences between the panels. However, the following section will review how some of the dynamics operating between farm households and wider networks and communities did reveal differences between the groups that might inform a social capitals-based approach. That is, there are some qualitative differences in the types (if not so much the quantities) of social capital that each panel would access.

In summary, these three dynamics that were identified as important in other studies, did not emerge from the ARGOS data as means of demonstrating important differences in social practice between the different panels of growers. However, this does not mean that they were not important. More likely was that either the ARGOS methodology and the structure of the overall panel design (and the sample sizes involved) limited the capacity to make meaningful comparisons or that there were specific dynamics in the New Zealand context to the study which may have made them less relevant. What these three dimensions did show, however, was that strong differences between the industry sectors in total overwhelmed some effects that might otherwise be observable from the panel differences. This immediately suggests that there is a broad structuring effect of industry sector that must be accounted for alongside the upcoming demonstration of panels differences associated with different market audit disciplines.

The following sections now turn to those social dynamics that did reveal differences between the panels. 


\section{Community and Grower Networks}

This area proved to be sociologically important, but was only moderately aligned with the management panels. Across all the households and sectors, issues of community, off-farm linkages and networks were key elements of the wider social environment in which participants lived (Hunt et al. 2005, 2006). The strongest evidence of actual panel difference involved the broader community orientation and networking style of the organic farmers, and this was also highly mediated by sector. For example, the kiwifruit sector had a strong organic grower organisation that was influential in that sector. The dairy sector included a nascent organic grower organisation which operated more as an interest group without similar relevance to the whole of the sector. In the sheep/beef sector, the comparable group was predicated on group marketing of organic meat outside the established sector organisations (Rosin et al. 2010). In summary, grower networks were important to the panels in all three sectors - particularly the organic panel - but highly mediated by the prevailing industry sector practices, culture and options.

\section{Commercial, Economic and Craft Orientations}

This set of dynamics produced a mixed result. The issue of 'craft' was apparent, but tended to be associated with diverse individual approaches rather than any one set of audit disciplines (Hunt et al. $2005,2006)$. One interesting result did reveal a difference between different management system panels. This came from examining potential trade-offs in grower orientation towards business/commercial goals as against environmental outcomes from their enterprises. The integrated sheep/beef, integrated gold kiwifruit and conventional dairy panels all demonstrated a preparedness to prioritise commercial returns over environmental outcomes. This was particularly pronounced when compared with the respective organic panels in each sector (Hunt et al. 2005, 2006, Rosin et al. 2010).

\section{Learning, Skill and Expertise}

In this area, there was a shared body of core practices that reflects a more general orientation of New Zealand producers: prioritisation of experience-based skill development and authority, reliance on local knowledge, proactive seeking of new information by individual producers, and a relative openness to information in farm journals and industry publications (Hunt et al. 2005, 2006, Rosin et al. 2010). As with many of these dynamics there were clear panel differences, but again they were strongly influenced by different industry sectors. In each sector, panels were characterised by different social practices around learning and skills, but these were not consistent across the sectors. This can be clearly seen with the integrated panels. In the kiwifruit sector, the integrated green panel demonstrated conformance with a 'comfortable' and prescribed set of practices when compared to organic or integrated gold panellists. Such a difference was also very evident in the comparison of a more conservative conventional sheep/beef panel with the more innovative integrated sheep/beef panel. In these sectors, members of integrated panels were distinct from their colleagues, but in potentially opposite ways: one was highly conservative and 'comfortable', the others were innovative and dynamic.

The organic panels were also distinctive, albeit defined according to unique characteristics within each sector. Organic kiwifruit producers were more independent of industry information and expertise and accorded greater authority to experienced organic growers or independent experts. In 
contrast, the newness of organic production in the dairy and sheep/beef sectors initiated different dynamics. Organic dairy producers were highly dependent on organic certifiers' information and training or, where present, established organic farmers. The organic sheep/beef producers generally relied on experimentation and internet or print resources (Rosin et al. 2010). All three organic panels were different to their wider sectors, but also different to each other.

\section{Sense of Place and Symbolic 'Look' of Farmscape}

The 'sense of place' demonstrated by the ARGOS panellists was most clearly evident in issues around the symbolic 'look' of their property - again mediated by industry sector. The relatively nonintensive overall production system limited the scope for sheep/beef farmers to pursue radically different management systems, likely explaining the lack of difference in the visual appearance of the farms in this sector. In contrast, strong differences were exhibited by the kiwifruit panels. This reflected the desire of many of the organic orchardists to encourage a 'messy' orchard with less frequently-mown sward and associated increases in biodiversity. The integrated green panellists generally preferred a 'clean and tidy' orchard appearance while the integrated gold panellists wanted an orchard that symbolically demonstrated their innovativeness (Hunt 2010).

\section{Grower Stress and Wellbeing}

Grower stress was a salient factor across all the industry sectors which were experiencing - at different times in the project - different causes of stress. In the sheep/beef sector, the project coincided with a prolonged period of low incomes. Those in the organic and integrated sheep/beef panels felt relatively more empowered to cope with financial hardship as they were more engaged with their customers and more proactively responding to economic opportunities compared to the more passive strategy of the conventional growers who sought to outlast difficult times (Hunt et al. 2006). A different dynamic emerged in the rather more prosperous dairy sector where those converting to organic practices experienced social stress having stepped outside the acceptable norms of the wider industry culture. This group also faced the challenges of caring for the health of their cows in new and less proven ways (however, this was counteracted to an extent by some who were delighted to have taken this step) (Mortlock and Hunt 2008, Rosin 2008). Similar issues (especially the attrition rate of stock that was not adapted to organic management) were recognised by organic sheep/beef farmers, although most had come to terms with this during their longer participation in the organic sector (Hunt et al. 2006).

\section{Grower Identity and Change}

Issues of grower identity were interesting - with a range of differences (often subtle) being identified. At one level, strong differences emerged between the pastoral farming sectors (sheep/beef, dairy) and the horticultural sector (kiwifruit). At the same time, identity dynamics varied from individual to individual. Interesting issues around the way in which orchardists personified their orchards (Hunt 2009, 2010) revealed a lot about identity and land management and conformed to some extent to a pattern related to the panels. Integrated green orchardists tended to be more traditional and did not like change whereas integrated gold orchardists were more likely to be innovative and take risks. This distinction was mitigated to some extent in cases where the gold orchardist also owned green kiwifruit orchards. Identity became much more salient in differentiating the panels through a subsequent realigning of data around issues of 'good 
farming'. These analyses arrived at the general conclusion that, while 'identity' as an organic, integrated or conventional grower had subtle interactions with the panel data, it was not the determinative driver of other social dynamics.

\section{Indicators/Feedbacks of On-Farm Processes}

A very productive arena of enquiry emerged around what kinds of feedback or indicators of farm health, success, or good management were deployed by different producers. Early interviews demonstrated that the panels of farmers and orchardists were often deploying different sets of indicators and observing different feedbacks in their farming systems (Hunt et al. 2005, 2006). For example, the organic panels in each sector emphasised a broader set of soil qualities (including soil biota in addition to mineral fertility) as integral to judging overall health of the property. The integrated green kiwifruit panel used feedbacks that were more likely to focus on the increasing presence of native bird species as an indicator of environmental health on their properties. Relative production (in comparison with peers and over time) was an important indicator for all panels, particularly integrated gold kiwifruit and for the dairy sector (Hunt et al. 2005, Rosin 2008, Rosin et al. 2007a, 2007b). In addition to placing greater value on environmental outcomes, organic panellists were often able to justify lower production by referring to the financial benefits associated with lower production costs (especially in the dairy sector) and organic price premiums. The clear relationship between social practices around indicators/feedbacks and the management system panels suggests that this line of enquiry is well worth continuing.

\section{Positioning Towards Nature/Environment}

An important area of differentiation between panels involved the producers' subjective positioning in relation to nature/environment both on their properties and in a wider context. This area of social practice provided the strongest panel differences across the research instruments, distinguishing the organic panels from the other management systems. Members of the organic panels across all the sectors more consistently privileged nature in their management decisions and emphasised their environmental responsibilities and impacts. This sentiment was often expressed as the intent to 'work with nature' as opposed to exerting control over it, although this was articulated in a similar manner by participants in the other sheep/beef panels. In addition, the organic panellists more generally prioritised maintaining and improving environmental health and more readily acknowledged the role of their management activities within wider environmental dynamics - both regional and global.

While the organic panellists were distinctive, this set of dynamics was very important across other panels as well. An important subgroup of 'green conventional' farmers identified in national survey responses (Fairweather et al. 2009c) were represented in the ARGOS qualitative data by farmers and orchardists expressing such an orientation by prioritising a specific set of environmental outcomes: bird biodiversity as an indicator of orchard health or the overall amenity value of trees and other features like wetlands as hunting resources in their farmscapes (McLeod et al. 2006). The members of the non-organic panels were also more likely to refer to a need to balance environmental concerns with economic viability and practicality. While the organic panels were most distinctive in this area, other panels did express different ways of being 'green'.

\section{Farming Management Approaches/Farming Styles}


Compared to the separate components of a farm management approach - like indicators/feedbacks, or environmental orientation - its wider configuration or 'farming style' provided some insights to differences between panels. Across all the sectors organic panellists exhibited a greater range of strategies in response to environmental constraints on farm management and, in the causal mapping results, expressed a more 'systems oriented' approach to their farm/orchard management. These panel differences again showed interesting variation by sector. For example, the sheep/beef sector exhibited clear distinctions in management approaches: organic sheep/beef producers centred environmental concerns in their overall farming system; integrated producers saw audit compliance as one key signifier of good management (alongside pasture condition and animal growth rate and health); and conventional panellists were more conservative in terms of altering established practices in the sector. Due in part to such differences, each panel articulated intriguingly different understandings of their farm system, the prioritisation of its components and their capacity to operationalise and strategise within it.

\section{Differentiating and Framing Social Practice in the Management System Panels}

The nine dynamics reported above turned out to be a useful starting point for uncovering social differences between the panels. The second stage of this analysis is to generalise across the categories to identify the strongest clustering of difference. The result is that the strongest differences can be aggregated around three key areas of management panel differentiation. In this summarisation, rather than focusing on the specific differences between organic and integrated panellists, the emphasis is placed on the main social practices and dynamics that differentiated between any of the panels. In short, these are the strongest differences in social practice associated with taking different market audit approaches (or not) to farming sustainably.

First, in the area of knowledge networks and learning there were differences across management systems in:

- styles of engagement with specific networks,

- the ways that farmers gained knowledge, and who they considered to be legitimate 'experts'.

Second, there were important differences in farmers' subjectivity and identity:

- individual producer's subjective positioning towards the environment/nature,

- the symbolic look of farms and orchards in terms of differences between styles of performative practice in landscape management, particularly in relation to managing a messy as against a tidy appearance of the property,

- other identity dynamics like orientation towards industry goals, tradition, and life goals.

Finally, there were differences in the role of environment in farm management practice or other specific dynamics within farm management: 
- the relative willingness to trade-off economic and environmental goals in achieving farm outcomes,

- The centrality of environmental health within representations of farming systems,

- The response to environmental dynamics and constraints within particular farming styles,

- The kinds of feedbacks being observed in farming systems,

- farmers' experiences of social and/or financial stress.

What starts to emerge across the large body of data is a clear sense that there is a demonstrable body of social practice associated with the pursuit of sustainable agriculture under the disciplines of various audit schemes. The social data in the ARGOS project does identify a clear set of social differences around networks, subjectivities and farm management practices that differentiates growers who are organic, integrated or neither. This, in itself, is an important finding in a field where empirical data on the social dynamics of sustainable agriculture are not abundant. However, the scale and integrated nature of the ARGOS data allows for a more comprehensive analysis. The rest of this article will discuss how the ARGOS research findings challenge some existing theoretical framings of the social character of sustainable agriculture.

At the start of this article, the ACAP work of Beus and Dunlap (1990,1991,1994) was used to demonstrate some of the implicit framings of an older style of sociological analysis of sustainable agriculture. There are two important assumptions buried within this framing. First, the ACAP approach comfortably operates within a dichotomous binary between 'alternative' and 'conventional' paradigms of production. Even where the specific terminology of paradigms is absent, subsequent commentators on alternative agriculture have had no hesitation in mobilising blunt, and strictly bounded categories of 'organic' and 'conventional' practice. ${ }^{11}$ Second, ACAP posed a powerful framing of identity/paradigm as being highly determinative of ecological practice and having a strong degree of internal coherence and integration. This fitted strongly into the then prevailing understanding deployed within environmental politics in the US (summarised by JacksonSmith and Buttel 2003) and with the wider suspicion regarding the legitimacy of new 'pragmatic' organic producers as against 'committed' or philosophically-pure ones.

The ARGOS research data presented in this article allows no such simple categorisation of social practice. The three key areas of difference in the ARGOS data - around knowledge networks and learning, subjectivity/identity and the role of the environment in farm management practice - could all be forced into an ACAP dichotomoy, or be aligned with a dichotomised ideal type of 'organic' versus 'conventional' in ways that are characteristic of many other analyses. The patterning of the ARGOS results does not, however, conform to the expected outcomes implicit in this framing of paradigms or categories of practice. All of these attributes were actually spread across the three management panels (albeit unevenly), and few producers exhibited a homogenously constructed identity which then strongly correlated with all the other positive attributes sought in an ACAP style framing. It makes no sense in the context of the ARGOS data to describe someone as an 'organic

${ }^{11}$ In fact, the entire 'conventionalisation' thesis is premised on exactly this kind of categorisation. 
farmer'. Rather, there are various and dynamic bodies of organic social practice that both cohere within and move across the categorical boundaries implied by such a term.

Despite the confounding of earlier categorisation of social practice within neatly bounded entities like organic and conventional, analysis of the ARGOS data still resulted in observed differences in social practice that are potentially highly important in realising beneficial ecological outcomes on farms/orchards. The following sections will turn to examining how this particular pattern of results can be understood in a way which will allow us to reframe our research approach concerning the social practice of sustainable agriculture.

\section{Beyond Categories of Organic and Conventional Social Practice: Towards Dynamic Co-Production?}

A number of prior publications from the ARGOS social research team have grappled with the problem identified at the end of the last section. Put simply, how do 'organic', 'conventional' and 'integrated' operate as social practices once we cease to conceptualise them as simple, categorical, and somehow determinative? Fairweather et al. (2009c) identified a group of 'green' conventional farmers in New Zealand thus undermining a comfortable use of the category 'conventional' to describe the environmental practice of many producers. Similarly, Campbell et al. (2009) in reviewing preliminary data from across the ARGOS project argued for the need to move beyond the organic/conventional binary. Rosin and Campbell (2009) also articulated that, in current settings, what was being considered 'organic' was not a natural attribute of the paradigms within which farmers operated (and expressed in practice) but was being constructed with reference to multiple justifications mobilised by diverse actors at different points of agri-food systems. The sum of these findings is that, while social dynamics are important to understanding sustainable praxis, they do not conform to any kind of dichotomy between organic and conventional or any simple explanatory framework that assumes a coherent and internally consistent (and ecologically determinative) identity for organic or conventional producers. The categorical assumptions inherent to the organic/conventional binary are further confounded by the existence of the types of 'integrated' producers that form an integral part of the ARGOS research framework and whose absence represents a glaring gap in existing social scientific narratives of sustainable agricultural practice.

In light of these ongoing questions in the ARGOS social research over several years, the final stage of analysis of the data collected in the first six years of the project's life is an attempt to reconceptualise how bodies of organic, integrated and (less coherently) conventional practice are being produced. If we have to abandon these older categorical framings of the social practice of sustainable agriculture, how do we explain the social production of the kinds of patterns that were identified in the previous section? Further, if these patterns in the social data do not cohere around dichotomies like organic and conventional or around cleanly delineated and homogenous grower 'identities', then how are we to situate these differences within wider understandings of how to achieve sustainable praxis?

The argument posed in the final part of this article is that reframing these findings through the lens of dynamic co-production provides a much more plausible way of understanding the social character of sustainable agriculture. In the following section we will demonstrate that the social practice of sustainable agriculture is being co-produced from the interplay of four dynamics (in no specific 
order): 1) individual subjectivity, 2) audit disciplines, 3) industry culture and context and, potentially, 4) time since conversion. While there are clearly also other influences co-producing particular patterns of difference within social practice, these four emerge as the most important in the ARGOS data to date.

\section{Subjectivity, Identity and Homogenous Paradigms}

The ARGOS data demonstrate that, while particular subjective orientations to the environment, nature and risk are correlated with adoption of a particular audit system, they by no means determine that outcome. Producers who showed greater propensity to privilege commitments to environmental sustainability, to recognise the benefits of working with nature, to understand their farm as a complex human/natural system and to centre the environment in their farm system, did tend to cluster solely within the organic panel. However, there were also a number of producers with significant green motivations and orientations that feature in the other panels, including an important minority of 'conventional' producers. Being green doesn't automatically correlate with being organic, but being organic does strongly correlate with being green.

Individual subjectivity is therefore influential on much of the differentiation of social practice of ARGOS producers, but is not determinative of grower adoption of particular audit disciplines or the social practice of sustainable agriculture. Clearly there is, at the very least, some co-production of environmental practice on farms/orchards emerging between the subjectivity/identity of producers and wider audit disciplines.

\section{Audit Disciplines}

The fundamental structure of the ARGOS project involved groups of producers methodologically organised according to panels defined by management approach. This made the influence of audit disciplines in differentiating social practice strongly apparent. However, while there were significant (both in the qualitative and quantitative data) differences between the management panels (as articulated in the previous section), these were not consistent across all panels of the same type. ${ }^{12}$ For example, in only a few of these aspects of social practice did the observed differences distinguish organic growers from the other panels in all three industry sectors. Exceptions included the style and range of feedbacks being observed in farming systems. In that case, organic panellists in all sectors tended to give much more attention to soil biota as a feature of soil health as well as moderating their reference to overall production as an indicator of good farming performance. Similarly, organic panellists in all sectors gave greater weight to abstract environmental qualities within farmer subjectivity and placed greater value on environmental gains in trade-offs between environmental and economic outcomes in their farm management decision-making. In contrast, other than their conservative avoidance of audited practice, no consistent dynamic strongly differentiated all conventional panellists from the other panels. Finally, and perhaps the most intriguing of these findings, the integrated producers in kiwifruit and in sheep/beef demonstrated some distinctive qualities within each sector; but strikingly these were often different between sectors.

\footnotetext{
${ }^{12}$ It is also important to note that a key finding was that we actually found similarities between the panels on many measures.
} 
We suggest that it is no coincidence that organic certification demarcates the only consistent crosssector (kiwifruit, sheep/beef and dairy) findings. It is, rather, very evident that this consistency is largely a product of those attributes with the strongest direct linkage to specific requirements of the actual organic audit disciplines - soil quality and health (which is directly measured in organic audits), comparatively reduced production and a relative privileging of environmental outcomes in farm management (also the direct focus of aspects of generic organic audit disciplines). One important conclusion from this observation is that audit disciplines are not only providing a particular pathway or opportunity for producers with particular subjective orientations and strategies to express sustainable practice (providing a type of symbolic capital), they are also clearly shaping how that sustainable practice is being subjectively mobilised. It is, demonstrably for both organic and integrated audits, a process of co-production between identity/subjectivity and audit discipline.

This insight alone does not, however, explain all the unexpected complexity that emerged in the ARGOS data. If ARGOS is demonstrating the dynamic co-production of outcomes, one of the coproducers is arguably also the industry sector within which producers are embedded.

\section{Industry Culture and Context}

While the methodology of the ARGOS longitudinal panel design emphasised the influence of audit disciplines through comparison of different management panels, a secondary effect of the project structure was that all producers were situated in panels that were both defined by management system and industry sector. This had not been a key feature driving the ARGOS design - and was used mainly for pragmatic reasons; but, as the ARGOS analysis proceeded, it became clear that both industry sector and management system were driving differences in the results.

For example, in the areas of broad demographic differences (gender, age, education, ethnicity, religion), institutional structure (class, ownership and enterprise structure of farming) and social capital, there were interesting differences; but this differentiation was distributed across all members of one industry and did not cluster around specific differences between organic, integrated and other producers. Put simply, there were important social attributes that were vastly more reflective of the participants' identity as a sheep/beef, dairy or kiwifruit producer than by their management system, that is, organic or integrated or neither. Similarly, dynamics around producer networks, learning and skills development, expertise and stress were strongly mediated by industry sector.

The effect of industry sector was also highly pronounced in terms of which market audit options were available. All the industries in ARGOS are export-oriented and key industry groups (ZESPRI in kiwifruit, Fonterra in dairy, large meat companies in sheep/beef) dictate the available suite of market audits. Hence, for example, alongside organic there is no 'conventional' option for kiwifruit producers, only different styles of integrated production. Large companies do not promote organic audits in the sheep/beef sector and, in negotiation with targeted retailers, strongly determine whether integrated management is a strong or weak audit. The dairy industry lacked a non-organic 'green' option as Fonterra has chosen to promote organic as its main environmental alternative. In brief, the industry sectors were highly influential due both to the availability of audit options and to the wider impact of industry culture on producer subjectivity. 
It is important to note that these options are not simply imposed on producers. In each sector, key organic growers (and other organic professionals like consultants) have been influential in the decisions and style of organic audit adopted in each sector, a dynamic that is also observable in relation to integrated systems (but with less influence by producers and more by other actors) (see Rosin, et al. 2007a, 2007b, 2007c). A further interesting point is the clear degree to which the audit systems within each sector can be demonstrated to have influenced each other with, for example, considerable two-way transfer of management techniques between organic and integrated kiwifruit management.

What emerges is a new configuration of social practice within each sector, strongly influenced by industry structures and options, but also constituted out of social relations and negotiations between producers, audit systems and particular production environments. Rosin (2008) describes the reconfiguration of these conventions of production as a new 'spirit of farming' in each sector. Seen in this light, the character of each sector in New Zealand is partly co-produced out of the subjectivities, evolution of audit disciplines and wider industry practice and culture.

\section{Time}

A factor that is currently only subtly observable in the ARGOS data, but has the potential to emerge as the longitudinal study design continues, is the length of time since adoption of an audit - both by industry sectors in toto and by individual producers. A number of the key differences that emerged that were not attributable to subjectivity, audit discipline or industry are potentially explicable simply as a consequence of elapsed time. For example, there were distinct characteristics of organic dairy producers, their approaches, management styles, learning style and networks that reflect the relative newness of organic audits to both the industry and the producers themselves. Similarly, at least one kiwifruit panel had experienced dramatic shifts in stress levels over time (associated also with changing industry conditions). In a situation where outcomes are being co-produced, there is arguably a time element in both the interaction of participation in audit schemes and producer identity/subjectivity and the way in which audit disciplines evolve in particular industry contexts. These are only preliminary observations, and the longitudinal design of ARGOS will provide compelling opportunities to revisit these producers and sectors to see how many of these dynamics change over time. ${ }^{13}$

\section{Discussion: The Social Practice of Sustainable Agriculture under Audit Disciplines}

At the outset of this article, it was recognised that there has been a limited amount of empirical research into the social dynamics and practices of sustainable agriculture and very little indeed into those emerging at the household and farm-level around the incorporation of producers into new audit disciplines. The evidence presented here demonstrates that there are emerging, and distinctive, bodies of social practice around these audit disciplines and that these demonstrate

\footnotetext{
${ }^{13}$ Another interesting methodological challenge involves refining the methodology to account for the possible influence of some of the dynamics that were found to be non-significant in this dataset. The demographic profile, farm enterprise structure and influence of social capital were all excluded as non-significant, although it might be interesting to pursue the degree to which their relative insignificance was simply an artefact of the ARGOS methodology or even influenced by the characteristics of New Zealand as a farming country.
} 
qualities that one might expect of producers becoming involved in sustainable agriculture. They are embedded in particular kinds of social networks and tend to privilege particular kinds of authority and sources of knowledge. They are subjectively more positive towards the environment and also centre the environment in their 'farming system'. They tend to look for particular kinds of feedback in their farming system and are more prepared to value environmental relative to economic goals. All these subjective attributes of sustainable producers - their practices, management approach, learning and networking - accord with the narratives of sustainable agriculture found in other indepth studies of sustainable agriculture such as Hassanein (1999) or Bell (2004). What is different in this particular set of results is that they have emerged within a highly commercialised, exportoriented, unregulated and extensively audited agricultural context.

The broad implications of this are worth some reflection. Much of the recent elaboration of new forms of sustainable agriculture has taken place under the aegis of new environmental audits like certified organic or GLOBALG.A.P. and has been accompanied by a backlash from supporters of an older, localised, more social movement-driven context for sustainable agriculture. Critics like Michael Pollan have argued that the emergent cohort of certified producers, processors and retailers have formed an Organic Industrial Complex that has betrayed the 'authentic' social practice of organics. Proponents of the 'conventionalisation thesis' or the twin trajectories of 'bifurcation' also mobilise framings that suggest an older 'authentic' version of organic practice, which in relation to new and less trustworthy modes, can categorically dichotomise those who practice organic farming. Within this discourse, the wider adoption of 'integrated' production standards like GLOBALG.A.P. seems barely worthy of consideration as a serious contributor to the development of a praxis of sustainable agriculture.

The ARGOS results demonstrate that new audit disciplines are opening up space for forms of social practice to emerge in ways that resemble much of the wider (and more admired) practice of sustainable agriculture. At one level, these results strongly undermine the old framing - typified by ACAP - in which a coherent identity/paradigm of alternative practice was the necessary precondition for 'genuine' sustainable praxis to emerge. However, the opposite tendency is also not true. The new audit disciplines are not determinative in securing outcomes in social practice. Rather, audit disciplines are operating as one aspect of the dynamic co-production of social practice in sustainable agriculture alongside producer subjectivities and industry dynamics, all of which are evolving over time.

These results serve to open important new lines of enquiry within the emerging sociology of sustainable agriculture. First, the ARGOS data provide a compelling site for examining this interaction between subjectivity and audit systems. The specific dynamics of subjectivity under audit have already been examined for each sector (see Hunt et al. 2005, 2006, Rosin et al. 2007a, 2007b, 2007c). In this article these results establish the intriguing degree to which audit systems consistently open up spaces for new subjective positioning by farmers (although the resulting subjectivities are not necessarily consistent across sectors and audits). While the assumption from earlier theorisation that organic subjectivities would be consistent across different industry groups has been somewhat undermined (e.g., between the kiwifruit and dairy sectors), an even more intriguing set of results is visible in the different outcomes of adopting integrated management systems. The integrated audit disciplines clearly interact with farmer subjectivity and there is demonstrable evidence that a particular integrated subjectivity is operating in the different sectors. 
However, the actual content of that 'integrated' subject position is dramatically different between the green kiwifruit producers and the integrated producers in the sheep/beef sector. One coheres around the most conservative and risk-averse group of producers, the other around the most interventionist, risk prone and progressive producers. This finding deserves much fuller elaboration and a subsequent publication will elaborate how the social practice of integrated management is emerging in different sectors.

The second emerging line of enquiry concerns the more explicit linkage of social practice with actual ecological outcomes on farms and orchards. Having rejected the simple causal assumption that coherently constructed bearers of organic (or alternative) identities, by aligning with wider paradigms of practice, automatically generate better outcomes (certainly when compared with their 'conventionalised' counterparts), a fascinating gap in our knowledge becomes apparent. It is very rare to find in-depth social research into practitioners of new 'sustainable' practices that also engages in a comprehensive analysis of the ecological outcomes on farms. Where this has been done, it usually involves single case studies or a single set of paired farms. The transdisciplinary nature of the ARGOS project allows a completely different scope of enquiry by evaluating ecological, financial and management dynamics alongside in-depth social data (Hunt et al. 2010). Current work is addressing this topic (Hunt et al. 2011). The use of the framework of 'co-production' of social practice has proved useful to explain the particular patterns that emerged in the ARGOS data; however, it also leaves open the question as to how the agro-ecologies of each production system are strongly contributing to the co-production of sustainable agriculture practices.

An interesting question arises about the connection between social practice and ecological outcomes. If we no longer maintain the premise that a farmer must be totally and homogenously socialised into 'alternative' subjectivities to realise beneficial ecological outcomes (as was the expectation of the paradigmatic approach of ACAP), is it possible that quite small differences in social practice (like a singular difference confined to environmental positioning or observation of feedbacks in farming systems) can actually equate to significant ecological gains? In other words, is the pursuit of a unique, specifically philosophical adoption of alternative practice misplaced, and should we be more comfortable with a more pragmatic, piecemeal approach to shifting the practice of sustainable production? There has been little research conducted that is capable of directly answering this question - although it is the intent of the ARGOS group to contribute significantly to this enquiry.

This article provides an initial analysis of social practice within groups of producers utilising different management systems (some of which are subject to audit disciplines) as part of the ARGOS research project in New Zealand. Clearly, six years of data collected from multiple research instruments is not amenable to comprehensive summary in one article. Rather, the intent of this analysis was to use an initial set of 12 social dynamics to elaborate alternative ways of understanding the social practice of sustainable agriculture. This process provides clear support for authors who reject older models of homogenous farmer identity, as well as those who reject categorical organic/conventional dichotomies as determinative in the social practice of sustainable agriculture. This analytical step further demonstrates that differentiation in industry sectors, time elapsed since conversion, farmer subjectivities and styles of audit discipline is interacting to co-produce outcomes on the farms and orchards in the ARGOS project. As the first in a series of analyses of the whole ARGOS dataset, this article has opened two key lines of inquiry relevant to our understandings of the interaction among 
these dynamics. It has also placed some important concepts and new framings into the social research toolkit around sustainable agriculture under audit discipline. The task ahead is to both elaborate these insights to the New Zealand specific data and examine the potential for other sociocultural contexts to change some of the outcomes in the co-production of sustainable praxis in agriculture.

\section{References}

Allen, P., Van Dusen, D., Jackelyn, L., and Gleissman, S. (1991). 'Integrating social, environmental, and economic issues in sustainable agriculture.' American Journal of Alternative Agriculture 6(1): 3439.

Allen, P. and Kovach, M. (2000). The Capitalist Composition of Organic: The Potential of Markets in Fulfilling the Promise of Organic Agriculture. Agriculture and Human Values 17, 221-232.

Bell, M.M. (2004). Farming for Us All: Practical Agriculture \& the Cultivation of Sustainability. Pennsylvania: The Pennsylvania State University Press.

Beus, C. E. and Dunlap, R. E. (1990). 'Conventional versus Alternative Agriculture: The Paradigmatic Roots of the Debate. Rural Sociology. Vol. 55:590-616.

Beus, C. E. and Dunlap, R. E. (1991). 'Measuring Adherence to Alternative vs. Conventional Agricultural Paradigms: A Proposed Scale.' Rural Sociology 56: 432-460.

Beus, C. E. and Dunlap, R. E. (1994). 'Agricultural Paradigms and the Practice of Agriculture.' Rural Sociology 59: 620-653.

Buck, D., Getz, C. and Guthman, J. (1997) From farm to table: the organic vegetable commodity chain of Northern California. Sociologia Ruralis 37, 3-19.

Burton, R. J. F. (2004a). "Seeing through the 'good farmer's eyes': towards developing an understanding of the social symbolic value of 'productivist' behaviour." Sociologia Ruralis 44(2): 195-214.

Burton, R.J.F. (2004b). Reconceptualising the 'behavioural approach' in agricultural studies: the socio-psychological perspective. Journal of Rural Studies 20, 359-371.

Busch, L., and C. Bain. (2004). New! Improved? The Transformation of the Global Agrifood System. Rural Sociology 69(3): 321-346.

Campbell, H. (1997). Organic Food Exporting in New Zealand: The emerging relationship between sustainable agriculture, corporate agri-business and globalising food networks. Pp. 51-72 in H. De Haan, B. Kasimis, and M. Redclift eds. Sustainable Rural Development Ashgate, Aldershot.

Campbell, H. (2005). The rise and rise of EurepGAP: The European (re)invention of colonial food relations? International Journal of Sociology of Agriculture and Food 13(2): 6-19. 
Campbell, H. and Coombes, B. (1999). Green protectionism and the exporting of organic fresh fruit and vegetables from New Zealand: crisis experiments in the breakdown of Fordist trade and agricultural policies. Rural Sociology 64(2): 302-319.

Campbell, H. and Liepins, R. (2001). 'Naming Organics: understanding organic standards in New Zealand as a discursive field' Sociologia Ruralis.41, 1, pp. 21-39

Campbell, H., J. Fairweather, L. Hunt, C. McLeod, and C. Rosin. (2004). Social dimensions of sustainable agriculture: a rationale for social research in ARGOS. ARGOS Working Paper 2, www.argos.org.nz

Campbell. H. McLeod, C. and Rosin, C. (2006). Auditing Sustainability: The Impact of EurepGAP in New Zealand. Pp. 157-173 in Holt, G. and Reed, M. (eds) Organic Agriculture: A Sociological Perspective. CABI: Oxon.

Campbell, H. and Le Heron R. (2007). Supermarkets, Producers and Audit Technologies: The Constitutive Micro-Politics of Food, Legitimacy and Governance. Pp. 131-153 in Lawrence, G. and Burch. D. (eds) Supermarkets and Agri-Food Supply Chains: Transformations in the Production and Consumption of Foods. Edward Elgar: London.

Campbell, H., Rosin, C., Norton, S., Carey, P., Benge, J. and Moller, H. (2009). 'Examining the Mythologies of Organics: Moving beyond the Organic/Conventional Binary?' Pp. 238-251 in Lawrence, G., Lyons, K, and Wallington, T. (eds.) Food Security, Nutrition and Sustainability. Earthscan: London.

Campbell, H. and Rosin, C. (2011). The 'Organic Industrial Complex': An Ontological Expedition Through Commercial Organic Agriculture In New Zealand. Journal of Rural Studies. doi:10.1016/j.jrurstud.2011.04.003.

Carolan, M. S. (2005). 'Barriers to the Adoption of Sustainable Agriculture on Rented Land: An examination of contesting social fields.' Rural Sociology 70(3): 387-413.

Coombes, B., and Campbell, H. (1998). Dependent Reproduction of Alternative Modes of Agriculture: Organic Farming in New Zealand. Sociologia Ruralis 38(2): 127-145.

Darnhofer, I., Schneeberger, W. and Freyer, B. (2005). Converting or not converting to organic farming in Austria: Farmer types and their rationale. Agriculture and Human Values. Vol 22(1): 39-52.

Egoz, S. (2000). 'Clean and Green but Messy: the Contested Landscape of New Zealand's Organic Farms.' Oral History (Spring): 63-74.

Fairweather, J. R. (1999). Understanding how farmers choose between organic and conventional production: Results from New Zealand and policy implications. Agriculture and Human Values, 16(1): 51-63.

Fairweather J. R. (2009), Farmer models of socio-ecologic systems: application of causal mapping across multiple locations. Ecological Modelling. http://dx.doi.org/10.1016/j.ecolmodel.2009.10.026 
Fairweather, J. and Hunt, L. (2009). Can Farmers Map their Farm System?: Causal Mapping and the Sustainability of Sheep/Beef Farm Systems in New Zealand. Agriculture and Human Values. http://www.springerlink.com/openurl.asp?genre=article\&id=doi:10.1007/s10460-009-9252-3

Fairweather, J., L. Hunt, C. Rosin, H. Campbell, J. Benge, and M. J. Watts. (2006) Understanding kiwifruit management using causal mapping. ARGOS Research Report 06/09, www.argos.org.nz

Fairweather, J., L. Hunt, C. Rosin, H. Campbell, and D. Lucock. (2007a) Understanding sheep/beef farm management using causal mapping: development and application of a two-stage approach. ARGOS Research Report 07/02, www.argos.org.nz

Fairweather, J., L. Hunt, A. Cook, C. Rosin, and H. Campbell. (2007b) The representativeness of ARGOS panels and between panels comparisons. ARGOS Research Report 07/03. www.argos.org.nz

Fairweather, J., L. Hunt, A. Cook, C. Rosin and H. Campbell (2007c) New Zealand Farmer and Grower Attitude and Opinion Survey: Analysis by Sector and Management System. ARGOS Research Report 07/07. www.argos.org.nz

Fairweather, J., L. Hunt, C. Rosin, J. Benge and H. Campbell (2009a), Kiwifruit causal mapping in 2008: Comparisons to 2005 to other sectors. ARGOS Research Report 09/01. www.argos.org.nz Fairweather, J., L. Hunt, J. Benge, H. Campbell, G. Greer, D. Lucock, J. Manhire, S. Meadows, H. Moller, C. Rosin, C. Saunders and Y. Fukuda (2009b) New Zealand Farmer and Orchardist Attitude and Opinion Survey 2008. ARGOS Research Report 09/02. www.argos.org.nz

Fairweather, J., C. Rosin, L. Hunt and H. Campbell. (2009c). 'Are conventional farmers conventional? Analysis of the environmental orientation of conventional New Zealand farmers. Rural Sociology 74(3): 430-454.

Falconer, K. (2000). 'Farm-level constraints on agri-environmental scheme participation: a transactional perspective.' Journal of Rural Studies 16: 379-394.

Flora, C. B., ed. (2001). Interactions Between Agroecosystems and Rural Communities. Boca Raton: CRC Press.

Fulkerson, G. (2008). Alternative and Conventional Agricultural Representations in the United States: Results from Two National Mail Surveys, 1992 and 2001. Southern Rural Sociology, Vol 23(1): 298321.

Fulponi, L. (2006). Private voluntary standards in the food system: The perspective of major food retailers in OECD countries. Food Policy 31(1): 1-13.

Guthman, J. (1998). Regulating Meaning, Appropriating Nature: The Codification of Californian Organic Agriculture. Antipode 30, pp. 135-154.

Guthman, J. (2004) Agrarian Dreams: The Paradox of Organic Farming in California. University of California Press, Berkeley.

Hall, A. and Mogyorody, V. (2007). Organic Farming, Gender and the Labor Process. Rural Sociology Vol 72(2): 289-316. 
Hassanein, N. (1999). Changing the Way America Farms: Knowledge and Community in the Sustainable Agriculture Movement. University of Nebraska Press: Lincoln.

Hassanein, N. and J. R. Kloppenburg Jr (1995). "Where the Grass Grows Again: Knowledge Exchange in the Sustainable Agriculture Movement." Rural Sociology 60(4): 721-740.

Hatanaka, M., C. Bain, and L. Busch. (2005). Third-party certification in the global agrifood system. Food Policy 30: 354-369.

Henson, S., and T. Reardon. (2005). Private agri-food standards: Implications for food policy and the agri-food system. Food Policy 30: 241-253

Hinrichs, C. C. (1998). Sideline and lifeline: the cultural economy of maple syrup production. Rural Sociology $63(4): 507-532$.

Hinrichs, C. C. (2000). Embeddedness and local food systems: notes on two types of direct agricultural market. Journal of Rural Studies 16:295-303.

Holloway, L. (2002). 'Smallholding, hobby-farming, and commercial farming: ethical identities and the production of farming spaces.' Environment and Planning A 34: 2055-2070.

Hunt, L., C. Rosin, C. McLeod, M. Read, J. Fairweather, and H. Campbell. (2005). Understanding Approaches to Kiwifruit Production in New Zealand: Report on First Qualitative Interviews of ARGOS Kiwifruit Participants. ARGOS Research Report 05/01, www.argos.org.nz

Hunt, L., C. Rosin, M. Read, J. Fairweather, and H. Campbell. (2006). Understanding Approaches to Sheep/Beef Production in New Zealand: Report on First Qualitative Interviews of ARGOS Sheep/Beef Participants. In ARGOS Research Report 06/01, www.argos.org.nz

Hunt, L. (2009). Moving to the country for a graduated retirement: constructing new meaningful lives. In, Francesca Merlan and David Raftery (eds), Tracking Rural Change: community, policy and technology in Australia, New Zealand and Europe. Canberra: ANU E-Press. http://epress.anu.edu.au/tracking_citation.html Hunt, L. (2010). Interpreting orchardists' talk about their orchards: the good orchardists. Agriculture and Human Values 27(4): 415-426.

Hunt, L., Benge, J., Campbell, H., Fairweather, J., Greer, G., Lucock, D., Manhire, J., Moller, H., Reid, J., Rosin, C., and Saunders, C. (2010). Experiences of transdisciplinarity in research on agricultural sustainability. Paper presented to the $10^{\text {th }}$ European International Farming Systems Assoc Symposium, 4-7 July 2010, Vienna.

Hunt, L., Fairweather, J., Rosin, C., Campbell, H., Lucock, D. And Greer, G. (2011). Doing the unthinkable: linking farmer's breadth of view and adaptive propensity to the achievement of social, environmental and economic outcomes. Proceedings of the $18^{\text {th }}$ International Farm Management Association Congress 'Thriving in a global market: innovation, co-operation and leadership', Methven, Canterbury, New Zealand. 20-25 March 2011. Pp. 197-203.

Jackson, W. (1994) Becoming Native to This Place. Washington, D.C.: Counterpoint. 
Jackson-Smith, D. and Buttel, F. (2003). Social and Ecological Dimensions of the AlternativeConventional Agricultural Paradigm Scale. Rural Sociology, Vol 68(4): 513-530.

Jahn, G., M. Schramm, and A. Spiller. (2005). The reliability of certification: Quality labels as a consumer policy tool. Journal of Consumer Policy 28: 53-73.

Larner, W. and R. Le Heron, (2004). 'Global benchmarking: Participating 'at a distance' in the globalizing economy', in W. Larner and W. Walters (eds), Global Governmentality: Governing International Spaces, London: Routledge, pp. 212-232.

Larner, W., Le Heron, R. and Lewis, N. (2007). Co-constituting neoliberalism: Globalising Governmentalities and political projects in Aotearoa New Zealand. In Neoliberalisation: States, Networks and People, England, K. and Ward, K. (eds.). Routledge: London. pp. 233-247.

Le Heron, R. (2003). Creating food futures: Reflections on food governance issues in New Zealand's agri-food sector. Journal of Rural Studies 19: 111-125.

Le Heron, R. (2005). Reconstituting New Zealand's Agri-Food Chains for International Competitiveness. Pp. 52-65 in Fold, N. and Pritchard, W. (eds.) Cross Continental Food Chains. Routledge: London.

Le Heron, R. (2007). Globalisation, governance and post-structural political economy: perspectives from Australasia. Asia Pacific Viewpoint 48, pp. 26-40.

Liepins, R. (1995). 'Women in Agriculture: Advocates for a Gendered Sustainable Agriculture.' Australian Geographer 26(2): 118-126.

Liepins, R. and Campbell, H. (1997). 'Men and women as stakeholders in the initiation and implementation of sustainable farming practices: Organic agriculture in Canterbury. Studies in Rural Sustainability, Research Report No. 3, Department of Geography, University of Otago: Dunedin.

Lyson, T. A. (2004). Civic Agriculture: Reconnecting Farm, Food, and Community. Tufts University Press: Medford, MA.

Manhire, J., Campbell, H. and Fairweather, J. (2003). Pathways to Sustainability: Comparing Production Systems across Four Sectors of New Zealand Agriculture, CSAFE Discussion Paper no 2, Centre for the Study of Agriculture, Food and Environment, University of Otago, New Zealand.

McKenna, M., Roche, M. M. and Le Heron, R. (1998). "Sustaining the Fruits of Labour: a Comparative Localities Analysis of the Integrated Fruit Production Programme in New Zealand's Apple Industry." Journal of Rural Studies 14(4): 393-409.

McKenna, M. and Campbell. H. (1999). Strategies for Greening the New Zealand Pipfruit Industry: The Development of IFP and Organic Systems. Studies in Rural Sustainability Research Report No. 6. Dept of Anthropology: University of Otago.

McLeod, C., Hunt, L., Rosin, C., Fairweather, J., Cook, A. and Campbell, H. (2006). New Zealand Farmers and Wetlands.ARGOS Research Report 06/10, November 2006. www.argos.org.nz 
Meares, A. (1997). "Making the Transition from Conventional to Sustainable Agriculture: Gender, Social Movement Participation, and Quality of Life on the family farm." Rural Sociology 62:21-47.

Morgan, K., and J. Murdoch. (2000). “Organic vs. conventional agriculture: knowledge, power and innovation in the food chain." Geoforum: 31(2): 159-173.

Mortlock, B and L. Hunt. (2008). Linking farmer wellbeing and environmentally sustainable land use: a comparison between converting and organic conventional dairy farmer. ARGOS Research Report 08/03. www.argos.org.nz

Ondersteijn, C. J. M., Giesen, G. W. J., and Huirne, R. B. M. (2003). 'Identification of farmer characteristics and farm strategies explaining changes in environmental management and environmental and economic performance of dairy farms.' Agricultural Systems 78: 31-55.

Paterson, J. (2001). 'Institutional Organization, Stewardship, and Religious Resistance to Modern Agricultural Trends: the Christian Farmers' Movement in the Netherlands and in Canada.' Agricultural History 75 (3): 308-328.

Peter, G., Bell, M. M., Jarnagin, S., and Bauer, D, (2000). Coming Back Across the Fence: Masculinity and the Transition to Sustainable Agriculture. Rural Sociology 65(4): 215-233.

Pollan, M. (2001). 'Behind the organic-industrial complex', New York Times Magazine [http://www.nytimes.com/2001/05/13/magazine/130RGANIC.html].

Power, M. (1997). The audit society: Rituals of verification. Oxford: Oxford University Press.

Pretty, J. and Ward, H. (2001). Social Capital and the Environment. World Development 29(2): 209227.

Pretty, J. (2002). Agri-Culture: Reconnecting People, Land and Nature. Earthscan: London.

Read, M., L. Hunt, and J. Fairweather. (2005). Sketch Maps: Features and Issues Important for the Management of ARGOS Orchards and Farms. ARGOS Research Report 05/10, www.argos.org.nz

Rosin, C., H. Campbell and L. Hunt. (2007a). 'Audit Me This! Orchard-Level Effects of the EurepGAP Audit System on New Zealand Kiwifruit Producers'. Pp. 61-74 in Stringer, C. and Le Heron, R. AgriFood Commodity Chains and Globalising Networks. Ashgate: Avebury

Rosin, C., L. Hunt, H. Campbell and J. Fairweather. (2007b). There are Audits, and There are Audits: Response of New Zealand Kiwifruit Orchardists to the Implementation of Supermarket Initiated Audit Schemes. ARGOS Research Report No. 07/06. www.argos.org.nz

Rosin, C., Hunt, L., Campbell, H. and Fairweather, J. (2007c). Becoming the Audited: Response of New Zealand Sheep/Beef Farmers to the Introduction of Supermarket Initiated Audit Schemes. ARGOS Research Report No. 07/05. www.argos.org.nz

Rosin, C. (2008). The conventions of agri-environmental practice in New Zealand: farmers, retail driven audit schemes and a new Spirit of Farming. GeoJournal 73:45-54. 
Rosin, C. and Campbell, H. (2009). Beyond bifurcation: examining the conventions of organic agriculture in New Zealand. Journal of Rural Studies Vol 25(1): 35-47.

Rosin, C., Hunt, L., Fairweather, J. and Campbell, H. (2010). Social Objective Synthesis Report 2: Evidence of Social Differentiation Associated with the Choice of Management System in New Zealand Agriculture as Indicated by ARGOS Farmers/Orchardists. ARGOS Research Report 10/*. Agriculture Research Group on Sustainability: Christchurch.

Stofferahn, C. (2009). Personal, Farm and Value Orientations in Conversion to Organic Farming. Journal of Sustainable Agriculture. Vol 33: 862-884.

Sundkvist, A., R. Milestad, and A.-M. Jansson. (2005). On the importance of tightening feedback loops for sustainable development of food systems. Food Policy 30: 224-239.

Vanclay, F., P. Howden, L. Mesiti, and S. Glyde. (2006). The social and intellectual construction of farming styles: testing Dutch ideas in Australian agriculture. Sociologia Ruralis 46 (1):61-82.

Wilson, G. (1996). 'Farmer Environmental Attitudes and ESA Participation.' Geoforum 27(2): 115-131. 